Les actes de colloques du musée du quai

Histoire de l'art et anthropologie

\title{
Cultures en dialogue : options pour les musées du $\mathrm{XXI}^{\mathrm{e}}$ siècle
}

\section{Sally Price}

\section{(2) OpenEdition}

\section{Journals}

Édition électronique

URL : http://journals.openedition.org/actesbranly/352

DOI : 10.4000/actesbranly.352

ISSN : 2105-2735

\section{Éditeur}

Musée du quai Branly Jacques Chirac

\section{Référence électronique}

Sally Price, "Cultures en dialogue : options pour les musées du xxl ${ }^{e}$ siècle », Les actes de colloques du musée du quai Branly Jacques Chirac [En ligne], 1 | 2009, mis en ligne le 18 septembre 2009, consulté le 08 septembre 2020. URL : http://journals.openedition.org/actesbranly/352 ; DOI : https://doi.org/

10.4000/actesbranly.352

Ce document a été généré automatiquement le 8 septembre 2020

(c) Tous droits réservés 


\title{
Cultures en dialogue : options pour les musées du XXI ${ }^{\mathrm{e}}$ siècle
}

\author{
Sally Price
}

\section{NOTE DE L'AUTEUR}

Pour le soutien qu'ils ont prêté à cet essai, je remercie les organisateurs du colloque « Histoire de l'art et anthropologie » et le Reves Center for International Studies à l'université de William \& Mary.

1 Dans un double essai sur "l'appropriation indigène des choses européennes » et «l'appropriation européenne des choses indigènes », l'océaniste Nicholas Thomas fit remarquer : "To say black bottles were given does not tell us what was received ${ }^{1}$. "

2 Lorsque des biens matériels sont déplacés d'une culture à une autre (que ce soit en guise de cadeaux, d'objets volés, de butin de guerre ou dans d'autres conditions de transfert), leurs significations sont presque toujours laissées pour compte, ouvrant la voie à de nouvelles significations, répondant à de nouveaux contextes. La présence d'objets non-occidentaux dans des cabinets royaux et, plus tard, dans des musées maritimes (exposés côte à côte auprès de modèles de vaisseaux à voile) nous rappelle à quel point ces acquisitions faisaient partie du programme colonialiste.

3 Mais que faire de ces significations à partir du moment où notre monde se qualifie de «post-colonial » et que les ambitions impérialistes sont reléguées dans les placards de l'Histoire ? Ce dilemme, qui se trouve au cœur d'un tourbillon de questionnements dans le monde des musées du XXI ${ }^{\mathrm{e}}$ siècle, est l'objet de cet essai.

4 Les musées se sont toujours montrés sensibles au contexte idéologique et politique qui les entoure, s'adaptant au cours du temps lorsqu'il changeait. Pour ne citer que quelques-uns des exemples les plus connus, des objets utilisés dans les cérémonies du potlatch et confisqués par le gouvernement canadien lors de la répression politique des années 1920 furent rapatriés un demi-siècle plus tard dans deux musées locaux autochtones, alors que les droits des minorités commençaient à être à l'ordre du jour 
dans la sphère politique. Citons aussi l'exemple, en France, du musée du Trocadéro lorsque celui-ci est devenu le musée de l'Homme en 1937. On a alors remplacé les vitrines en bois par des vitrines en métal pour refléter le rôle prépondérant de la science dans la vie de la nation². Et dans les années 1990 à Paris encore, sur fond d'immigration croissante en Europe, un véritable jeu de chaises musicales a touché toute une palette d'institutions - mettant fin à celles-ci et amputant celles-la, créant de nouveaux lieux d'exposition et en restructurant d'autres.

5 Ce remue-ménage muséologique est partie prenante de l'histoire mouvementée des musées en France - une histoire qui a vu, par exemple, l'essor et la chute des collections ethnographiques du musée de l'Homme, la mutation du palais de la Porte Dorée de musée colonial en musée d'art, et l'arrivée, puis le départ, des arts et traditions populaires au Bois de Boulogne. Sans oublier le consentement contraint des conservateurs du musée du Louvre à l'entrée dans ce haut lieu de la culture de ce qui fut longtemps considéré comme les fétiches de sauvages. Tout cela préparait en fait le terrain de la plus récente et de la plus spectaculaire reconfiguration du paysage muséographique français : la création du musée du quai Branly³.

6 Si l'on considère cette histoire tout au long $\mathrm{du} \mathrm{xx}^{\mathrm{e}}$ siècle, on perçoit la disparition graduelle de la vision colonialiste et l'influence de cette disparition sur les musées. On peut se demander à partir de là comment la présentation d'autres cultures dans les musées se trouve modifiée par la relégation des ambitions impérialistes à un phénomène du passé. Et alors que la frontière entre ceux qui regardent et ceux qui sont regardés s'estompe progressivement, comment les musées ont-ils pris en charge la présentation de la différence culturelle au vu de ces changements? La réponse n'est évidemment pas univoque et quatre modèles semblent particulièrement pertinents pour étayer notre propos.

7 Une première possibilité s'attache à mettre en avant les qualités formelles des objets pour promouvoir la contemplation esthétique, bien à l'abri de toute contamination par excès de contextualisation. Cette approche les isole à la fois de leur fonction première dans leur lointaine culture d'origine, et de leur rôle en tant que butin du colonialisme. Présentés comme chefs-d'œuvre universels, ces objets sont nimbés d'un certain hiératisme, tandis que l'information ethnographique se confine à des catalogues ou à des bornes multimédia, délibérément éloignées des objets eux-mêmes.

8 Un deuxième modèle donne le rôle principal aux membres des cultures représentées ou à leurs descendants. Ce modèle leur accorde la primauté dans la prise de décisions, qu'il s'agisse d'exposition ou d'interprétation des objets. La forme la plus poussée de ce modèle est représentée par les musées entièrement placés sous la direction d'autochtones.

9 Un troisième modèle présente les objets comme vignettes d'un passé pré-colonial, purifié de l'intrusion modernisante. À partir de ce modèle, l'accent est mis sur les coiffures emplumées, les autels en l'honneur d'ancêtres et les "fétiches", en évitant soigneusement toute mention de bouteilles de Coca-Cola, de téléphones portables, ou de personnes victimes des ravages du SIDA.

10 Et enfin, un quatrième modèle privilégie l'histoire des rencontres entre indigènes et Européens et accorde une priorité aux circonstances d'acquisition des objets. L'accent est mis sur l'histoire de la production des connaissances au sujet des peuples qui ne font pas partie du supposé « monde européen ». 
11 Les débats des deux dernières décennies concernant la présentation des arts d'Afrique, d'Océanie et des Amériques ont accordé une attention croissante aux avantages et aux inconvénients de ces divers modèles. Ces débats portaient sur la question de savoir quels messages sur l'art et la différence culturelle ces différents modèles transmettaient. Le défi, bien sûr, est de tout vouloir embrasser à la fois : appréciation esthétique des objets exposés, appréciation de leur statut comme témoins d'un mode de vie et de visions culturelles particuliers et comme vestiges de l'histoire mondiale [...].

Bref... Si les débats d'il y a cent ans pouvaient s'exprimer haut et fort en termes d'opposition entre art et ethnologie, ceux d'aujourd'hui commencent à exiger une attention soutenue à la question «qui parle pour qui ? » et à celle des circonstances dans lesquelles les objets étaient collectés.

Portons maintenant notre attention sur le musée du quai Branly pour voir comment les différentes options ont été prises en compte, et comment elles pourraient être prises en compte dans le musée du quai Branly de l'avenir.

Dans le présent essai, je me propose de laisser de côté le premier modèle, en raison de l'existence du Pavillon des Sessions au Louvre. En effet, si, à Paris, un visiteur a envie de communier avec des œuvres d'une beauté à couper le souffle, présentées de façon magistrale, ou s'il a besoin d'avoir la confirmation du fait que les cultures noneuropéennes ont produit des chefs-d'œuvre mondiaux, alors l'exposition présentée au Louvre est là pour le satisfaire.

Passons alors au deuxième modèle, celui qui solliciterait l'autorité des autochtones. On sait que Jacques Chirac s'intéressait activement à la possibilité d'associer les autochtones aux instances décisionnaires du musée, sans avoir semble-t-il été entendu. On peut aller jusqu'à dire que, si le nouveau musée national de l'Indien Américain à Washington s'expose à la critique pour l'exclusion quasi totale de voix non-indigènes à sa direction, le musée du quai Branly penche fortement vers l'autre extrême. Je rêve pour ma part du jour où les textes didactiques, jusqu'à présent rédigés par une équipe essentiellement parisienne, seront complétés par d'autres, réalisés par des Africains, des Océaniens et des Aborigènes des deux Amériques.

16 Comme je n'ai pas assez de temps pour élaborer la liste de tous les changements souhaitables, je ne mentionnerai qu'un seul exemple. Dans une des vitrines du plateau des collections, le cartel correspondant à deux sculptures nkisi consiste en une citation extraite de La Sculpture nègre primitive de Paul Guillaume. Il va sans dire que, si P. Guillaume, marchand d'art primitif dans les années vingt, était un connaisseur distingué, il ne représente tout de même qu'un aperçu parisien des débuts $d u x^{e}$ siècle. Le choix de son texte pour rendre compte des réalités africaines ne peut que confirmer, pour les visiteurs du musée, l'impression qu'ils se trouvent dans un espace où la voix des artistes et de leur communauté d'origine est au second plan. Alors, dans le rêve que je fais d'un musée du quai Branly de demain, l'autorité d'un collectionneur d'art d'il y a cent ans devra absolument être complétée par une voix moins éloignée de la culture d'origine des objets.

17 Quant au troisième modèle, celui qui privilégie une vision des cultures avant l'arrivée des Européens : montons l'escalier en direction du centre multimédia du musée. Là, un visiteur peut s'informer sur les cultures représentées dans le musée à partir d'une grande variété de rubriques: shamanisme, chasse et cueillette, totémisme, parenté, sacrifice, rites d'initiation, mythes, classes d'âge et cannibalisme. Pour moi, cette liste 
évoque l'image de Franz Boas, filmant des danseurs de la côte nord-ouest, et qui tendait un drap blanc pour cacher les maisons modernes à l'arrière-plan !

L'objectif, il y a cent ans, était d'extraire l'essence authentique de chaque société primitive, la dépouillant de tout signe d'influence modernisante. Mais depuis Boas, l'ethnologie a progressé bien au-delà de cette vision statique et, de nos jours, on exige une appréciation de la nature dynamique des cultures. Donc, je rêve également de sources d'informations qui complètent le totémisme et le cannibalisme par d'autres sujets reflétant la vie actuelle de ces sociétés. Dans cette perspective, l'absence d'une rubrique me semble particulièrement troublante dans un musée du xxI ${ }^{\mathrm{e}}$ siècle, étant donné son importance centrale pour les peuples non-européens comme pour les chercheurs qui les étudient. C'est le tourisme. Le centre multimédia n'y fait aucune mention. Et tout aussi absents des bornes multimédia sont d'autres sujets d'intérêt central : l'esclavage, le colonialisme et l'histoire de la collecte d'objets.

Boli du Kono, Mali, bwa, collecté en 1931.

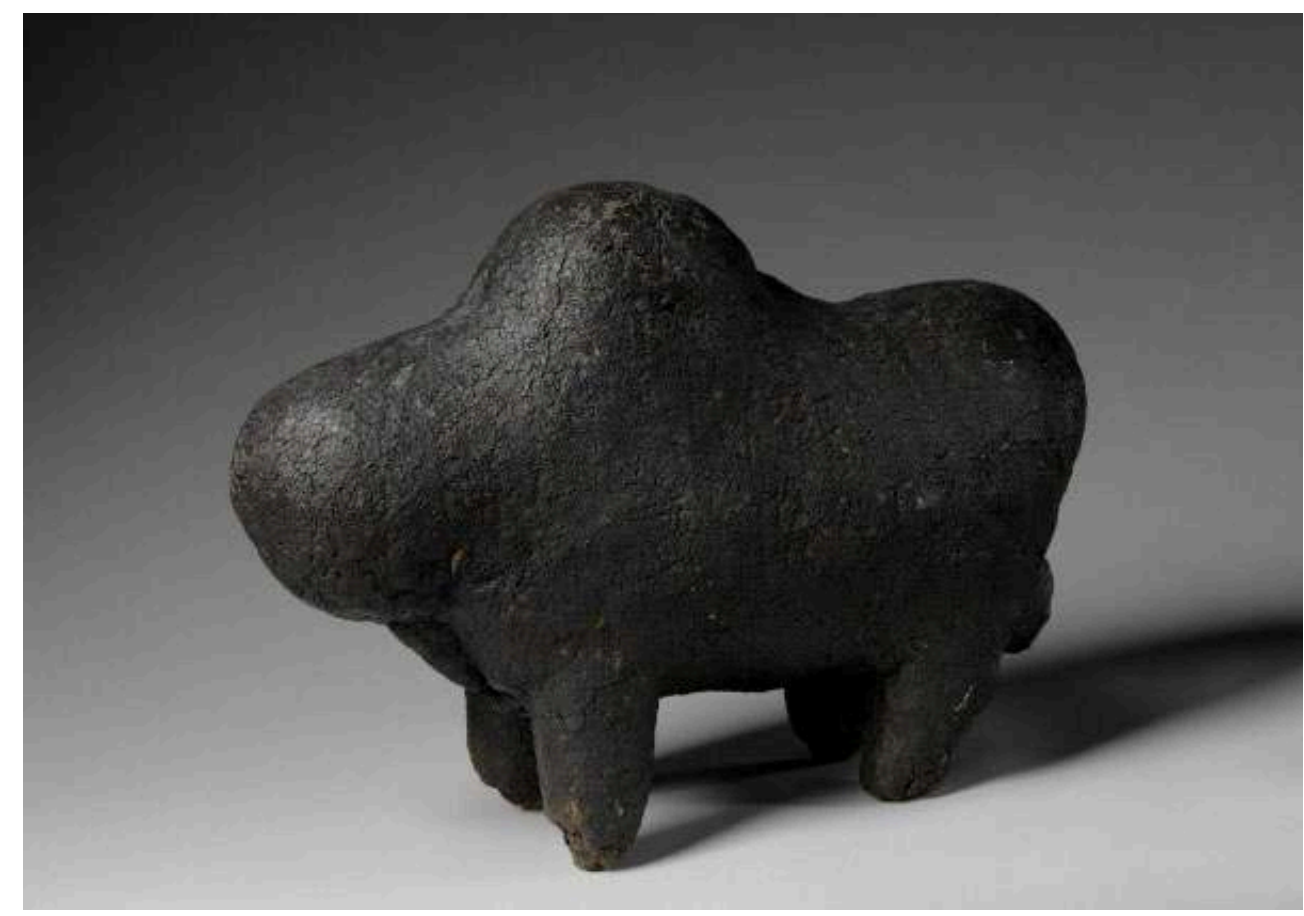

(c) musée du quai Branly

Ceci nous amène au dernier de mes quatre modèles. Cette option, qui met en avant l'histoire de l'acquisition des collections, alimentait des débats particulièrement animés au sein du Conseil scientifique de la mission de préfiguration. Car un musée comme le musée du quai Branly (en tant que projet présidentiel surtout) est difficilement dissociable d'un discours complaisant à l'égard de l'histoire de la nation française. Mais, dans le même temps, l'histoire de la collecte à l'ère coloniale (et parfois, de nos jours encore) ne permet pas toujours de soutenir ce discours. Prenons un seul exemple parmi les nombreux cas où l'histoire de l'acquisition d'un objet exposé dans le plateau des collections aurait pu servir comme point de départ à une réflexion sur les rapports post-coloniaux. Le cartel correspondant à un objet provenant de la mission DakarDjibouti dans les années trente précise que « Michel Leiris relate la découverte de ce Kono dans son sanctuaire » et cite son journal daté du 6 septembre 1931 : 
«Le réduit apparaît : à droite, des formes indéfinissables en une sorte de nougat brun qui n'est autre que du sang coagulé. Au milieu, une grande calebasse remplie d'objets hétéroclites [...]. À gauche, pendu au plafond au milieu d'une foule de calebasses, un paquet innommable, couvert de plumes de différents oiseaux et dans lequel Griaule, qui palpe, sent qu'il y a un masque. ${ }^{4}$ "

«Griaule décrète que, puisqu'on se moque décidément de nous, il faut, en représailles, nous livrer le Kono en échange de 10 francs, sous peine que la police soi-disant cachée dans le camion prenne le chef et les notables du village pour les conduire à San où ils s'expliqueront devant l'administration. Affreux chantage ! [...] Griaule et moi demandons que les hommes aillent chercher le Kono. Tout le monde refusant, nous y allons nous-mêmes, emballons l'objet saint dans la bâche, et sortons comme des voleurs. [Le lendemain, le rapt continue.] [...] enlèvement d'un deuxième Kono, que Griaule a repéré en s'introduisant subrepticement dans la case réservée. Mon cœur bat très fort car, depuis le scandale d'hier, je perçois avec plus d'acuité l'énormité de ce que nous commettons. [Plus tard on acquiert un troisième Kono.] Cette fois-ci c'est moi qui me charge tout seul de l'opération et pénètre dans le réduit sacré, le couteau de chasse de Lutte à la main [...] je constate avec une stupeur qui [...] se transforme en dégoût, qu'on se sent tout de même joliment sûr de soi lorsqu'on est un blanc et qu'on tient un couteau dans sa main. ${ }^{5}$ »

21 Ici, je me permets de souhaiter que le cartel soit un jour modifié dans deux sens : d'abord pour reconnaître le drame que Leiris raconte de manière si viscérale et, ensuite, pour signaler le combat qu'il a mené plus tard contre le pillage d'objets. Il m'est difficile d'imaginer une opportunité plus propice pour susciter une réflexion sur les pratiques qui ont alimenté les musées du monde. Comment mieux entrer dans un véritable « dialogue de cultures » qui ne serait ni une condamnation anachronique des pratiques coloniales, ni un effacement suspect de ces mêmes pratiques? Comme l'a écrit Benoît de L'Estoile :

« [...] un musée consacré aux arts et civilisations hors d'Occident est aujourd'hui nécessairement un musée post-colonial, au triple sens où la période coloniale est pour une grande part derrière nous, où notre actualité quotidienne s'inscrit pour une large part dans le prolongement des bouleversements coloniaux [...] et où le musée lui-même en est l'héritier matériel, de par ses collections, et spirituel, par la prégnance à la fois de notions (comme celle de "tribal") et de modalités de présentation venues de l'époque coloniale. [...] Il est donc nécessaire que le musée se confronte à l'histoire : pas seulement en ajoutant quelques dates ici ou là, ni en présentant les sociétés telles qu'elles étaient à l'époque de la Conquête, mais en donnant une place centrale à l'historicité. [...] Au lieu de prétendre effacer ce passé par la magie d'une refondation généreuse, il faut plutôt s'efforcer de faire prendre conscience au spectateur de tout ce qui structure ses schèmes de perceptions, souvent sans même qu'il s'en rende compte ${ }^{6}$.»

22 Mais quelles que soient ses priorités précises, tout musée qui expose des objets ethnographiques est confronté au même défi. Ce défi tient au fait que les objets portent, dans leur culture d'origine, des significations multiples et souvent très complexes, qui ne sont guère capables de survivre au passage à la vitrine du musée. Les organisateurs du colloque qui fait l'objet de ce propos ont bien reconnu ce constat, précisant dans leur appel à communications qu'ils recherchaient des réflexions sur "les différentes opérations de translation qui font passer l'artefact d'un "régime de valeur" [selon l'expression d'Arjun Appadurai] à un autre, ce qu'André Malraux appelle 
la "métamorphose" [...] les déplacements de sens qu'induit le passage du "terrain" ou "contexte d'origine" au musée ou au marché. " "

Dans le colloque, la communication de l'ethnologue Howard Morphy a répondu superbement à cette invitation, illustrant la densité sémantique et le pouvoir esthétique - bref, l'éblouissante richesse culturelle - de l'art du peuple yolngu en Australie. En revanche, une fois que cet art prend place dans un musée, il se trouve trop souvent dépouillé de toute la complexité qui a fait l'objet de l'intervention de Morphy en faveur d'un sommaire de quelques mots :

«L'expansion infinie de l'univers est représentée ici de manière littérale, sous la forme d'un ciel nocturne rempli d'étoiles, gan'yu. Les étoiles visibles à l'œil nu sont entourées de celles qu'occultent les profondeurs de l'espace. Les étoiles représentent les ancêtres et [l'œuvre de Gulumbu Yunupingu reproduite sur le mur du musée] est une métaphore de l'unité de tous les peuples. ${ }^{8}$ "

Ou encore, la leçon offerte par l'historienne de l'art Ruth Phillips le dernier jour du colloque démontra à quel point la séparation d'un masque africain du reste de son costume (que ce soit dans une photo, dans le salon d'un collectionneur ou dans une vitrine de musée) entrave toute compréhension de sa raison d'être.

Retranché des perceptions, des utilisations, des significations, et des associations historiques qu'il a connues dans son contexte d'origine, l'objet de musée s'expose à l'interprétation du spectateur, avec tout le bagage conceptuel que cela suppose. Comme j'ai essayé de le démontrer dans une publication antérieure ${ }^{9}$, les idées préconçues ne se limitent pas aux gens simples, incultes ou mal éduqués, mais entrent souvent en jeu même chez des amateurs d'art tout à fait sérieux, voire professionnels. Il suffit de citer le cas de Jean-Paul Barbier, membre du comité de préfiguration du musée du quai Branly ${ }^{10}$, décrit dans une émission de France Culture comme «le plus grand collectionneur [d'art primitif] du monde [...] mais aussi un ethnologue d'une érudition époustouflante $»^{11}$. En dépit de son érudition incontestée, ce connaisseur se montre capable de caractériser les artistes non-occidentaux selon des stéréotypes qu'on est tenté de qualifier de " grossiers »:

«L'Africain est un cultivateur. C'est un homme qui est attaché à la terre, qui vit par la terre, qui peine pour gagner sa subsistance. Et ce mal qu'il se donne, cette difficulté de confrontation se ressent dans sa sculpture. La sculpture africaine est la sculpture d'un homme qui souffre. Et c'est une chose qu'on doit refléter aussi lorsqu'on expose des œuvres africaines, on doit tenir compte de cette sensibilité particulière. [En revanche, les habitants des îles océaniennes] étaient des gens qui vivaient très facilement! En Océanie, vous avez des fruits à pain, vous avez des ignames, vous avez des quantités de tubercules, vous avez des fruits partout. Vous n'avez qu'à vous pencher pour ramasser dans la mer des coquillages énormes dans lesquels il y a un kilo de chair parfaitement comestible. Vous avez des poissons, vous pouvez les attraper à la lance sans même vous mouiller les cuisses. Vous vivez d'une manière qui n'a rien de la vie effroyable d'un paysan du Mali. Vous comprenez $?^{12} »$

On en vient à se poser la question suivante : si un connaisseur de la renommée de M. Barbier est capable de se laisser emporter par ce genre de portrait d'artistes nonoccidentaux, quelle pourra être la vision de la plupart des visiteurs qui montent la rampe du musée vers le plateau des collections? Comment imaginer que des idées préconçues (produits inévitables de la vie dans une société occidentale) soient absentes de la contemplation de l'objet? Comment soutenir l'idée que la séparation d'un objet de tous les "éléments de séduction» (terme que Jacques Kerchache a utilisé pour la 
contextualisation ethnographique et historique d'un objet ${ }^{13}$ ) favorise une compréhension de l'intention de l'artiste ? Comment maintenir l'illusion d'une " pure » contemplation esthétique qui ne soit pas encombrée de visions promulguées dans tous les domaines de la vie occidentale (cinéma, télévision, livres, journaux, et autres...) ?

La décision d'utiliser des cartels minimalistes (appellation, matériel, donateur, numéro d'inventaire...) et d'éloigner l'essentiel des données contextualisantes à des bornes multimédia à l'étage ou à des catalogues en vente dans la boutique représente une position très claire sur ces points et donne libre cours aux visions du monde exotique répandues en Occident. Je reconnais pleinement, avec Maurice Godelier, qu' ' un musée n'est pas un livre dont on lirait les pages collées sur les murs. Ce n'est pas non plus une université où on délivre des programmes d'enseignement $»^{14}$. Mais des musées de part et d'autre dans le monde attestent aujourd'hui du fait qu'il est tout à fait possible d'accorder une très forte voix aux peuples représentés, sans priver les représenteurs de la leur. Nous ne sommes plus à l'ère où Marx déclarait: "Ils ne peuvent pas se représenter ; il faut qu'ils soient représentés. ${ }^{15}$ " Au contraire, le xxi siècle s'annonce comme le moment de jouir, selon l'expression si heureuse du musée du quai Branly, d'un véritable "dialogue des cultures »: non pas d'un dialogue entre chefs d'État et diplomates, mais plutôt d'un dialogue avec les hommes et les femmes qui ont fait ces objets, ou avec leurs descendants.

Pour terminer, écoutons la sagesse de Mary Douglas, parlant peu avant sa mort dans l'auditorium Claude Lévi-Strauss :

"J'en reviens directement à l'excitation et à l'inspiration qu'a suscitées le premier discours de M. Chirac lorsqu'il a parlé de "dialogue" entre les cultures... Jusqu'ici, nous n'avons été capables de préserver le passé que pour les classes supérieures et moyennes, les classes instruites, les chercheurs que le passé intéresse, soit pour des raisons professionnelles, soit par tradition familiale. Mais ce qu'un musée ethnographique doit être capable de faire, c'est, d'une manière ou d'une autre, engager la conversation avec les descendants des peuples qui sont à l'origine de l'art, qui ont fabriqué ces merveilleux trésors que le musée protège et transmet à la génération suivante. Et qui sont-ils? Ce sont les immigrants, les réfugiés, les pauvres dans notre communauté, qui n'appartiennent pas à nos traditions occidentales [...]. Je pense que c'est le problème que nous devrions aborder dans ce musée [...]. On devrait créer au moins un jour dans le mois, le dimanche, ou plus souvent que cela, des opportunités de dialogue avec une population à laquelle appartient une collection ${ }^{16}$.»

\section{BIBLIOGRAPHIE}

Clément 2006 : Anice Clément, «À voix nue », France Culture, cinq entretiens avec JeanPaul Barbier, diffusés la semaine du 16-20 janvier 2006.

Daubert 2000 : Michel Daubert, « Arts lointains à Louvre ouvert », Télérama hors-série « Les Arts premiers entrent au Louvre », 2000, p. 8-16. 
Dubuc 1998 : Élise Dubuc, « Le Futur antérieur du musée de l’Homme », Gradhiva 24, 1998, p. 71-92.

Godelier 2002 : Maurice Godelier, « For the Museum Public: Combining the pleasures of art and knowledge », Barbour Lecture, University of Virginia, 2002.

Latour 2007 : Bruno Latour, Le Dialogue des cultures : Actes des rencontres inaugurales du musée du quai Branly, Paris, musée du quai Branly, 2007.

Leiris 1934 : Michel Leiris, L'Afrique fantôme, Paris, Gallimard, 1934.

L'Estoile 2003 : Benoît de L'Estoile, « Le Musée des Arts premiers face à l'histoire », dans Francisco Bethencourt, dir., Les Arts premiers, Paris, Centre culturel Calouste Gulbenkian/ Jean Touzot, 2003, p. 41-61.

Price 2006 : Sally Price, Arts primitifs, regards civilisés, Paris, École nationale supérieure des beauxarts, 2006

Price 2007 : Sally Price, Paris Primitive : Jacques Chirac's Museum on the Quai Branly, Chicago, University of Chicago Press, 2007.

Price et Jamin 1988 : Sally Price et Jean Jamin, « Entretien avec Michel Leiris », Gradhiva4, 1988, p. 28-56.

Said 1978 : Edward Said, Orientalism, New York, Pantheon Books, 1978.

Thomas 1991 : Nicholas Thomas, Entangled Objects : Exchange, Material Culture, and Colonialism in the Pacific, Cambridge MA, Harvard University Press, 1991.

\section{NOTES}

1. Thomas 1991, p. 108.

2. Price et Jamin 1988, p. 40.

3. Pour une élaboration de cette histoire, voir Price 2007.

4. Leiris 1934 , p. 81-82.

5. Ibid., p. 82-83.

6. L'Estoile 2003, p. 57-58.

7. Appel à communication du colloque "histoire de l'art et anthropologie », musée du quai Branly, 2007.

8. Mur du musée du quai Branly, rue de l'Université.

9. Price 2006.

10. Dubuc 1998, p. 87. J.-P. Barbier a reçu 40 millions de francs pour 276 objets d'art nigérians qui font maintenant partie des collections du musée du quai Branly.

11. Clément 2006.

12. Ibid.

13. "Nous sommes sans cesse confrontés à des appareils de séduction, c'est-à-dire, tout ce qui peut conditionner le regard et le distraire de la sculpture en soi. Je repousse toutes ces tentations qui nuisent au jugement critique et ne favorisent pas l'accès à l'œuvre où devrait transparaître uniquement l'intégrité de l'artiste, son projet, son geste, le courage de ses propositions plastiques, quelles que soient sa culture et la fonction, rituelle ou purement esthétique, de l'objet. Pour cela nul n'est besoin de traduction ethnographique. » (Jacques Kerchache, cité dans Daubert 2000, p. 16)

14. Godelier 2002.

15. Karl Marx, Le 18 brumaire de Louis-Napoléon Bonaparte (1852), cité dans Said 1978. 
16. Voir la transcription dans Latour 2007, p. 382-384. La réaction de Catherine Clément à la proposition de Mary Douglas était de dire que « c'est très peu français comme esprit ».

\section{RÉSUMÉS}

Parlant de l'appropriation d'objets européens en Océanie, Nicholas Thomas remarque : «To say that black bottles were given does not tell us what was received. » Lorsque des objets sont déplacés d'une culture à une autre (en cadeau, butin de guerre, collecte scientifique ou dans d'autres conditions de transfert), leurs significations sont presque toujours laissées derrière, ouvrant la voie à de nouvelles significations. La présence d'objets non occidentaux dans des cabinets royaux et dans des musées maritimes (exposés à côté de modèles de vaisseaux à voile) nous rappelle à quel point ces acquisitions faisaient partie du programme colonialiste. Mais que faire une fois que le monde se qualifie de " postcolonial » et que les ambitions impérialistes sont reléguées à une leçon d'Histoire? Essayer de reconstruire leurs significations originelles? Accepter que les Occidentaux ne les voient pas avec les mêmes yeux que leurs auteurs et les présenter comme œuvres d'art? Privilégier les perspectives des descendants des auteurs, tout en sachant que les significations ont pu se transformer même dans leur culture d'origine? Plusieurs réponses possibles à ces questions permettront de situer celle du musée du quai Branly dans le paysage des musées du XXI ${ }^{\mathrm{e}}$ siècle.

\section{INDEX}

Mots-clés : approche esthétique, approche ethnographique, collectionneurs, colonialisme, contextualisation, déontologie, Michel Leiris, musée du quai Branly, peuples autochtones, primitivisme

\section{AUTEUR}

\section{SALLY PRICE}

Sally Price, professeur d'ethnologie aux Etats-Unis, était directeur d'études invité à l'École des hautes études en sciences sociales en 2008. Elle est l'auteur de Arts primitifs, regards civilisés (éditions de l'École national supérieure des beaux-arts) et co-auteur de Romare Bearden : la dimension caribéenne et Les arts des Marrons (éditions Vents-d'ailleurs). Son livre sur le musée du quai Branly (Paris Primitive: Jacques Chirac's Museum on the Quai Branly) fut publié en anglais par les presses de l'université de Chicago en 2007. 